\title{
JUNSIBI

\section{PENGELOLAAN ARSIP DIGITAL SURAT MASUK DAN KELUAR MENGGUNAKAN TEKNIK DOCUMENT SCANNING, OPTICAL CHARACTER RECOGNITION, DAN DATA INDEXING}

\author{
Boy Firmansyah \\ Email: boy@ibi-k57.ac.id \\ Program Studi Informatika, Fakultas Ilmu Komputer \\ Institut Bisnis dan Informatika (IBI) Kosgoro 1957
}

\begin{abstract}
ABSTRAK
Pengelolaan arsip (berkas) surat masuk dan surat keluar selama ini rata-rata dilakukan secara konvensional berupa hardcopy atau lembaran kertas yang menyusahkan dalam hal pencarian surat jika sewaktu-waktu diperlukan. Surat masuk dalam beberapa tahun yang lalu akan lebih susah ditemukan jika tempat penyimpanannya berupa hardcopy baik karena makin menumpuknya arsip ataupun karena arsip surat yang tersimpan sudah rusak. Kerumitan dan kesulitan ini dapat diselesaikan dengan memanfaatkan kemajuan dibidang teknologi informasi yaitu komputerisasi untuk menangani arsip surat masuk dan keluar. Pengelolaan dengan pemanfaatan teknologi komputer tersebut bukan lagi berupa hardcopy (cetakan) atau lembaran kertas melainkan sudah berupa file (berkas) hasil pemindaian secara digital surat yang asli (sumber). Arsip hasil pemindaian akan direkam dengan kode tertentu agar memudahkan pada saat pencarian sehingga arsip (berkas) yang telah masuk pada beberapa tahun yang lalu tidak dalam keadaan rusak serta mudah dicari.

Kata Kunci: Sistem, Administrasi, Pengelolaan Surat, Arsip Digital, Scanning, OCR, Data Indexing
\end{abstract}

\section{PENDAHULUAN}

Pada pengarsipan dan pengelolaan arsip surat masuk dan keluar sampai saat ini masih dilakukan dengan cara konvensional berupa hardcopy yaitu sebuah format file yang sudah tercetak dalam bentuk print atau cetak lainnya yang menyusahkan dalam pencarian surat jika sewaktu-waktu akan dibutuhkan. Dokumentasi surat masuk dan keluar masih menggunakan pencatatan dalam buku agenda sebagai catatan record atau transaksi surat dan masih disimpan dalam map besar atau file box yang diurutkan berdasarkan nomor surat, atau nama surat. Selain itu dalam pengarsipan surat masuk dan surat keluar dibutuhkan pembuatan disposisi yang ditujukan ke pihak bersangkutan. Surat yang masuk dalam beberapa tahun lalu akan sulit dicari seandainya penyimpanan pada hardcopy karena dengan semakin bertumpuknya arsip atau disebabkan arsip surat masuk dan surat keluar yang telah rusak. Kesulitan tersebut dapat teratasi dengan memanfaatkan kemajuan dalam teknologi informasi agar arsip surat masuk dan surat keluar dapat terorganisasi dengan baik, maka diperlukan suatu pengolahan data yang lebih yang akurat, cepat dan efisien dengan menggunakan komputer yaitu merubah bentuk surat yang berbentuk hardcopy menjadi surat digital dan untuk aksesnya nanti bisa melalui aplikasi berbasis web yang bisa diakses oleh siapa saja, dimana saja, dan kapan saja dengan akses informasi yang sangat mudah. Hal ini diperlukan untuk memperoleh informasi yang handal, cepat, akurat, dan tepat waktu, merancang dan membuat Aplikasi Surat Masuk dan Surat Keluar dengan teknik Document Scanning, bagian tata usaha dapat dengan mudah memproses data di komputer dalam penginputan surat masuk dan surat keluar sehingga tidak akan terjadi kehilangan data, dan para pemohon dapat lebih mudah mencari data surat masuk dan keluar secara online melalui website.

\subsection{Pengertian Administrasi}

William Moris pada buku administrasi pendidikan karangan Prof. Dr. H. Asnawir mengatakan bahwa administrasi berasal dari bahasa latin yang terdiri atas "ad" serta "ministrare", dimana kata "ad" berarti dalam bahasa inggris adalah "to" yaitu ke atau kepada, dan sedangkan kata "ministrare" dalam bahasa Inggris yaitu "serve" berarti melayani, membantu atau mengarahkan. 


\subsection{Pengertian Arsip}

Menurut Kartika \& Sugiarto (2014:1) kearsipan adalah dasar daripada pemeliharaan surat, dan kearsipan mengandung suatu proses penyusunan serta penyimpanan surat-surat yang sedemikian rupa, agar surat tersebut dapat ditemukan kembali apabila diperlukan.

\subsection{Pengertian Surat}

Menurut Suryani, dkk (2015:2) Surat yaitu selembar kertas ataupun lebih yang dapat berisi percakapan (komunikasi) dimana disampaikan oleh seseorang terhadap orang lainnya, baik atas nama pribadi ataupun organisasi/instansi/ lembaga. Jadi, surat merupakan sebuah alat yang dipakai untuk berkomunikasi secara tertulis yang menggunakan persyaratan khusus (khas) sesuai aturan surat-menyurat.

\subsection{Pengertian Scanner dan Scanning}

Scanner yaitu sebuah alat yang digunakan untuk memindai sesuatu. Definisi Scanner menurut Crowther (1995: 1047) yaitu "a device that passes electronic waves through something in order to produce a picture of what is insideit". Scanner yaitu alat yang melewatkan suatu gelombang elektronik dari sesuatu agar dapat menghasilkan gambar tentang sesuatu yang ada di dalamnya. Dalam bahasa Inggris Scanning berarti membaca sepintas kilas. Menurut Soedarso (2004:84) scanning yaitu suatu teknik membaca agar mendapatkan informasi tanpa membaca lain-lainnya. Sehingga langsung ke masalah yang dituju yaitu fakta khusus serta informasi tertentu. Jika dikaitkan dengan alat scanner, maka scanning berarti kegiatan untuk membaca dari suatu bentuk analog dan merubahnya untuk mendapatkan informasi digital.

\section{METODE PENELITIAN}

\section{Analisis Sistem}

Sistem penginputan surat masuk dan surat keluar yang umum dimulai dari pihak luar mengirim surat, lalu pihak Tata Usaha membuat bukti tanda terima surat. Tata Usaha mencatat nomor surat dan tanggal masuk surat ke dalam buku agenda. Lalu bagian Tata Usaha mencatat surat masuk dibuku agenda kemudian mengirimnya ke pimpinan untuk dilihat. Lalu setelah itu bagian Tata Usaha menyimpan surat masuk ke dalam map atau box file.

Masalah akan terjadi pada saat pencarian surat, dimana ini dapat terjadi pada jangka waktu lama setelah surat di arsipkan, sehingga dapat menimbulkan beberapa permasalahan, seperti:

1) Pencarian dokumen yang lama, karena membuka dahulu data-data lama dan juga mencarinya satu persatu pada map atau box file.

2) Hilang atau rusaknya dokumen.

3) Terjadinya kesalahan penulisan nomor surat sehingga nomor surat sering kali tidak berurutan.

Untuk mengatasinya dapat dilakukan digitalisasi terhadap surat masuk maupun surat keluar. Proses digitalisasi dokumen tersebut menggunakan alat scanner 2 dimensi (2D) dimana nantinya dokumen fisik akan berubah menjadi bentuk dokumen digital.

\section{HASIL DAN PEMBAHASAN}

\subsection{Alur Manajemen Surat Secara Global}

Alur ini bersumber dari General Data (www.gdata.in). Adapun kegiatan manajemen surat dapat dilihat pada alur gambar 1. 


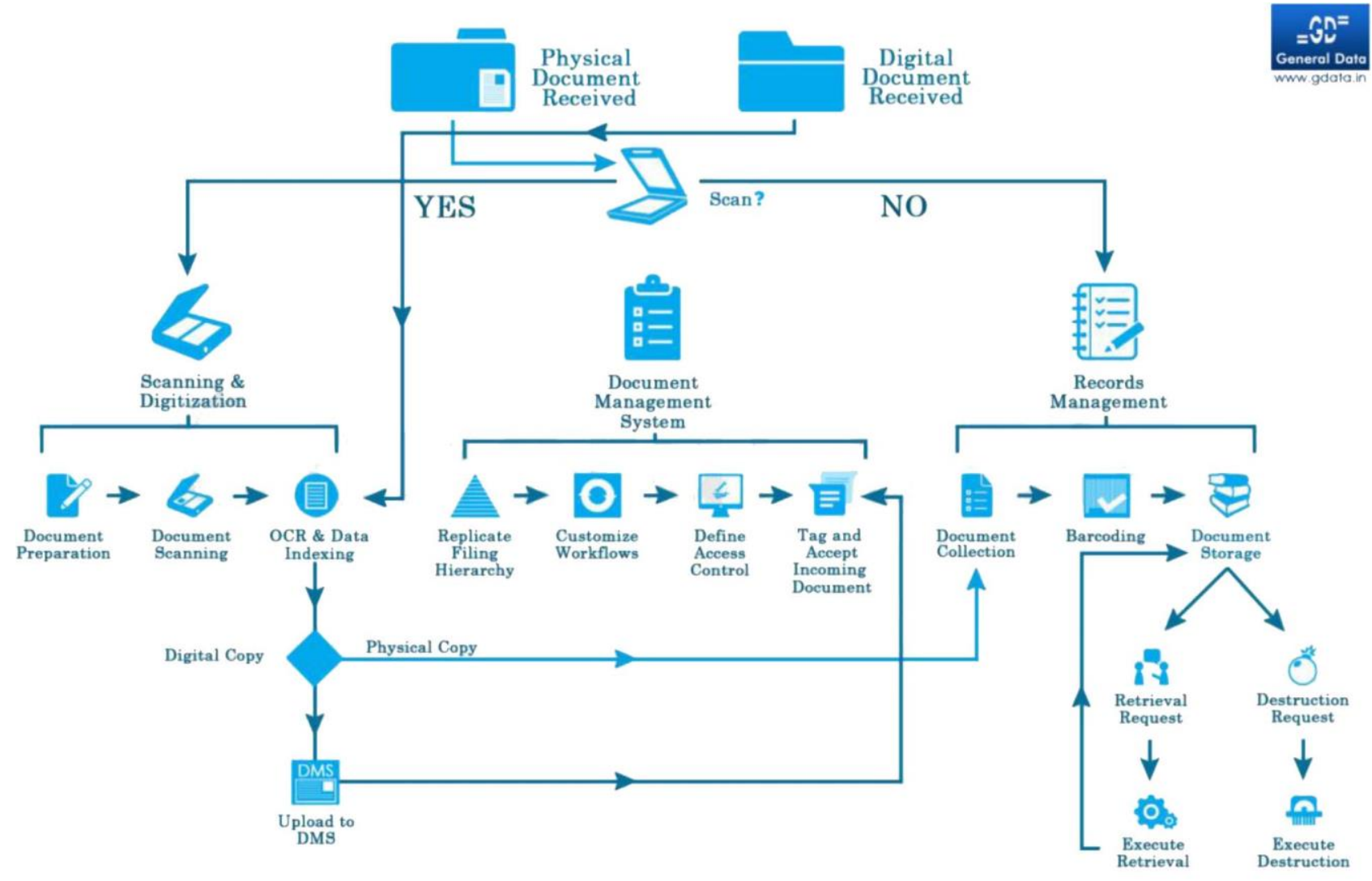

Infographic brought to you by General Data P. Limited

Gambar 1. Alur Penyimpanan Dokumen

\subsection{Proses Pemilihan Penyimpanan Dokumen}

Gambar 1 tersebut dapat dipecah sesuai kegiatannya agar dapat terlihat jelas proses administrasi surat yang ingin dilakukan. Lebih jelasnya dapat dilihat pada gambar $2 \mathrm{~s} / \mathrm{d}$ gambar 6 berikut:

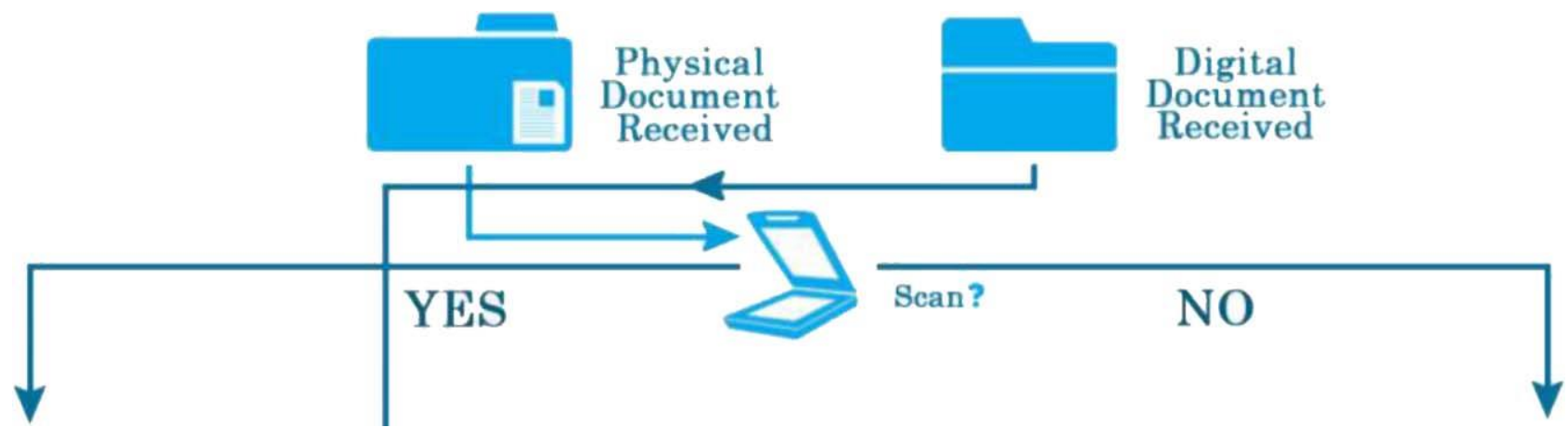

Gambar 2. Alur Pemilihan Penyimpanan Dokumen

Langkah awal adalah menentukan terlebih dahulu jenis penerimaan dokumen. Ada 2 (dua) macam jenis dokumen yang diterima, yaitu Physical Document Received dan Digital Document Received. Pada Physical Document Received berarti di sini kita menerima dokumen surat dalam bentuk fisik (kertas), sedangkan pada Digital Document Received berarti kita menerima kiriman surat sudah dalam bentuk file digital. Pada kasus surat yang diterima dalam bentuk fisik, maka kita akan masuk pada langkah untuk melakukan kegiatan digitalisasi dokumen, yaitu merekam ulang dokumen fisik menjadi bentuk file digital, melalui proses scanning (pemindaian). 


\subsection{Penyimpanan Dokumen Menggunakan Teknik Scanning}

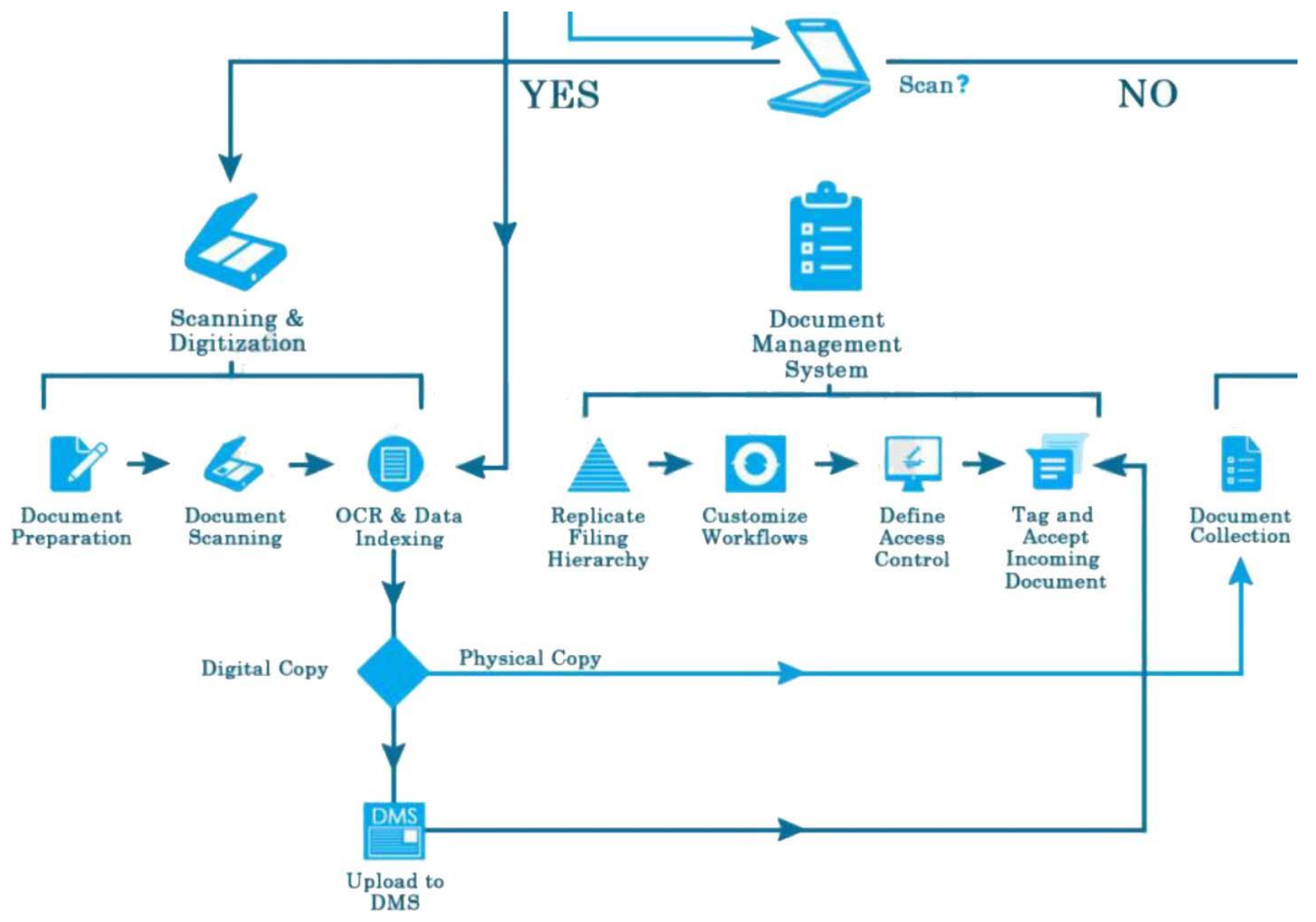

Gambar 3. Alur Penyimpanan Dokumen Dengan Teknik Scanning

Pada gambar 3 diatas terlihat kegiatan dari perubahan dokumen fisik menjadi file digital yang akan melalui proses Document Preparation, Document Scanning, serta OCR dan Data Indexing. Setelah itu akan ada 2 (dua) langkah pilihan, yaitu melakukan Digital Copy atau Physical Copy. Dokumen yang dilakukan kegiatan Digital Copy akan diolah pada bagian Document Management System, mulai dari Replicate Filing Hierarchy, Customize Workflows, Define Access Control, sampai Tag and Accept Incoming Document. Sedangkan pada pilihan kegiatan Physical Copy, maka dokumen akan dilanjutkan pada proses Document Collection.

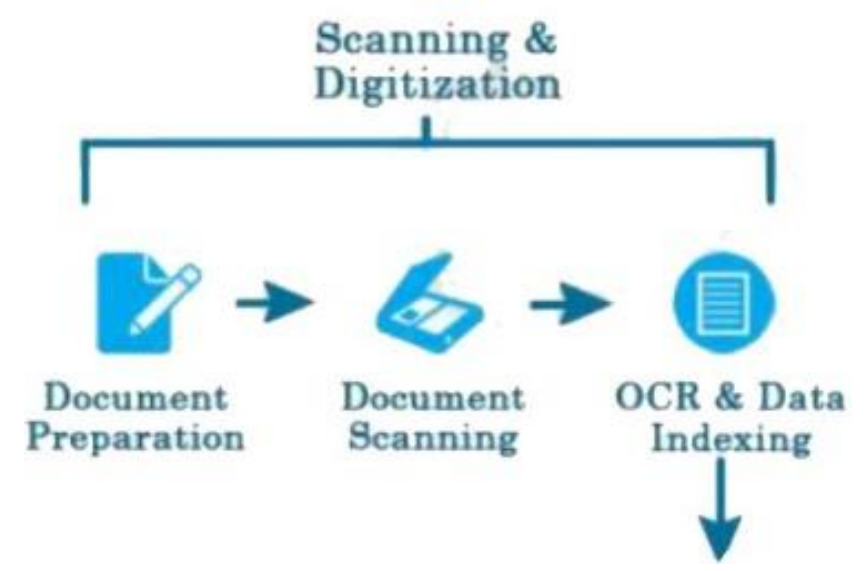

Gambar 4. Alur Proses Document Scanning 
Pada gambar 4 digambarkan tentang kegiatan dari Scanning and Digitization yang merupakan kegiatan perekaman data surat fisik menjadi bentuk file digital. Secara rincinya, kegiatan ini dimulai dari Document Preparation (Persiapan Dokumen), dimana kita memastikan bahwa dokumen surat tersebut bisa dilakukan proses digitalisasi. Selanjutnya masuk ke tahap Document Scanning (Pemindaian Dokumen), dimana disini kita memerlukan perangkat scanner (alat pindai) yang akan digunakan sebagai alat yang akan melakukan proses digitalisasi dokumen. Pada tahap ini perlu diperhatikan jenis alat pindai yang digunakan, proses instalasi driver (pengenal) pada perangkat komputer, dan beberapa konfigurasi yang dibutuhkan dalam proses pemindaian. Kemudian dalam proses pemindaian dokumen fisik yang memang berupa teks (dalam hal ini surat) akan dilakukan proses berikutnya yaitu Optical Character Recognition (OCR), atau proses pengenalan karakter optik, dimana disini dokumen surat yang sebagian besar berupa teks akan langsung dipetakan ke dalam bentuk teks digital, sehingga file digital yang dihasilkan nantinya adalah file digital yang sudah berformat teks, seperti .txt, .doc, .docx, .pdf, dan lain sebagainya. Keunggulannya adalah kita bisa melakukan proses editing (perubahan) terhadap dokumen teks digital tersebut.

\subsection{Document Management System}

Setelah proses OCR dan Data Indexing dilakukan, maka selanjutnya kita akan melakukan pengarsipan secara manual yaitu dengan cara mencetak surat tersebut ke dalam media kertas untuk kemudian diarsipkan pada arsip dokumen fisik. Hal ini tetap kita lakukan dalam rangka memenuhi kriteria pelaporan yang berlaku, yaitu pelaporan dalam bentuk fisik surat. Pelaporan jenis ini masih belum bisa ditinggalkan karena standar pelaporan surat-menyurat sekarang ini masih membutuhkan tempat penyimpanan fisik dalam bentuk kertas. Pada gambar 5 di bawah dapat dilihat kegiatan Physical Copy yang merupakan kegiatan pengumpulan dokumen surat dalam bentuk fisik. Setelah itu baru dilakukan pengunggahan dokumen surat digital ke Document Management System (DMS) yang dalam hal ini merupakan pengelolaan surat digital.

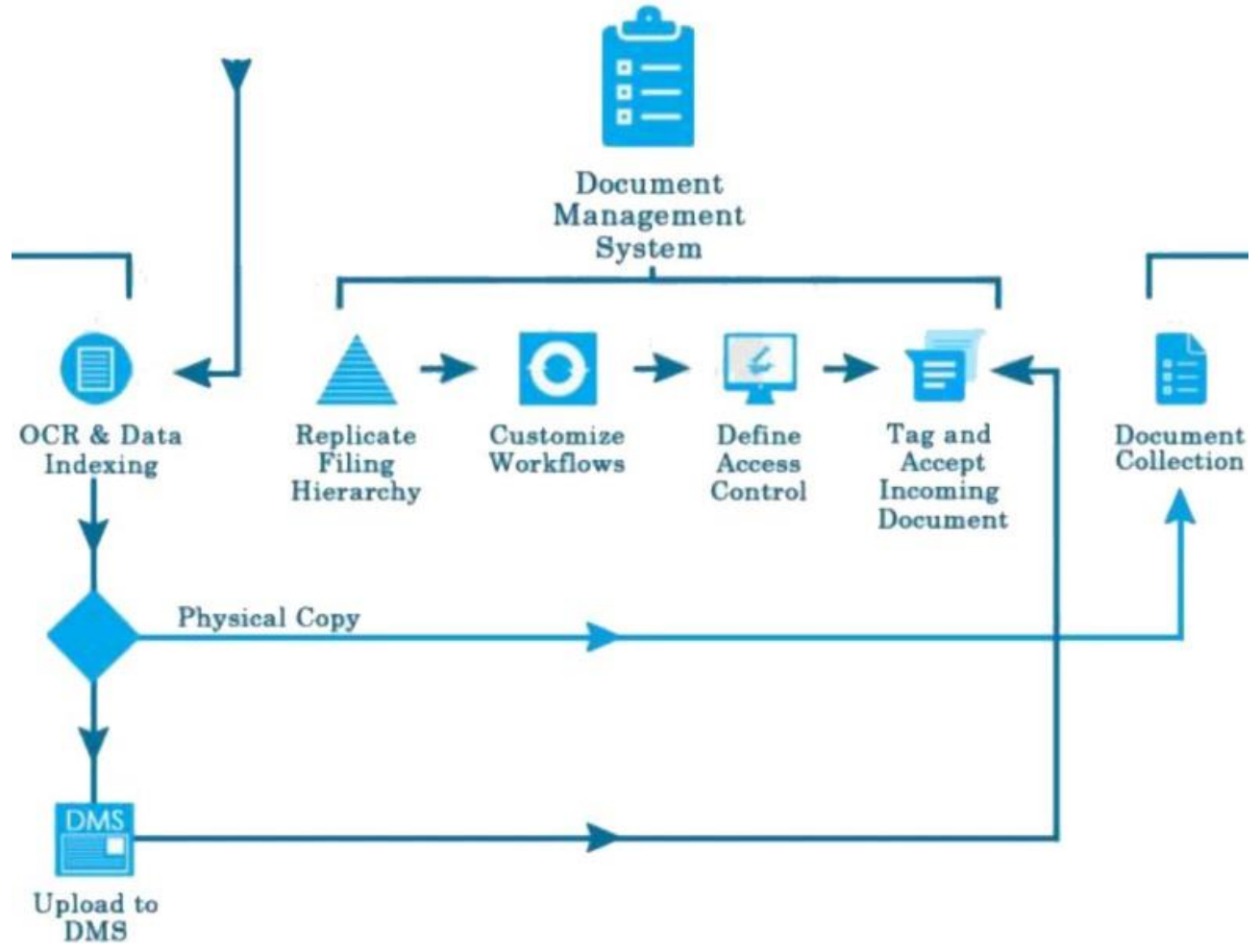

Gambar 5. Alur Sistem Manajemen Dokumen

Kegiatan DMS dimulai dari Replicate Filing Hierarchy, yaitu pengelompokan file surat yang akan digandakan. File surat ini akan dikelompokkan dalam direktori-direktori yang mencerminkan jenis surat tersebut. Disini bahkan akan dilakukan pengelompokan sampai sub-direktori dan tidak ada pembatasan level (tingkatan) sub-direktori nya karena disesuaikan dengan jenis surat tersebut. Lantas masuk pada kegiatan Customize Workflow yang mana merupakan langkah kustomisasi dari surat digital, yaitu melengkapi atribut- 
atribut yang melekat pada surat tersebut. Atribut tersebut mencirikan jenis surat yang akan disimpan pada direktori file surat. Kemudian dilakukan Define Acces Control, yaitu kegiatan mendefinisikan siapa yang berhak untuk mengakses file surat tersebut, dan akses apa yang diberikan. Jadi di sini akan ada file surat yang bisa diakses oleh seluruh user, tapi ada pula surat yang hanya dapat diakses oleh user-user tertentu. Baru proses DMS akan diakhiri oleh kegiatan Tag and Accept Incoming Document. Kegiatan ini merupakan kegiatan finalisasi pengarsipan file dokumen digital surat. Kegiatan ini ditandai dengan perekaman file surat digital sesuai dengan kriteria yang telah ditetapkan pada langkah-langkah DMS sebelumnya. Sampai sini langkah proses terhadap surat digital berakhir.

\subsection{Manajemen Arsip Surat Menggunakan Berkode}

Untuk selanjutnya akan dijelaskan langkah-langkah yang berhubungan dengan proses dokumentasi surat secara fisik. Untuk selengkapnya, dapat dilihat pada gambar 6 berikut ini.

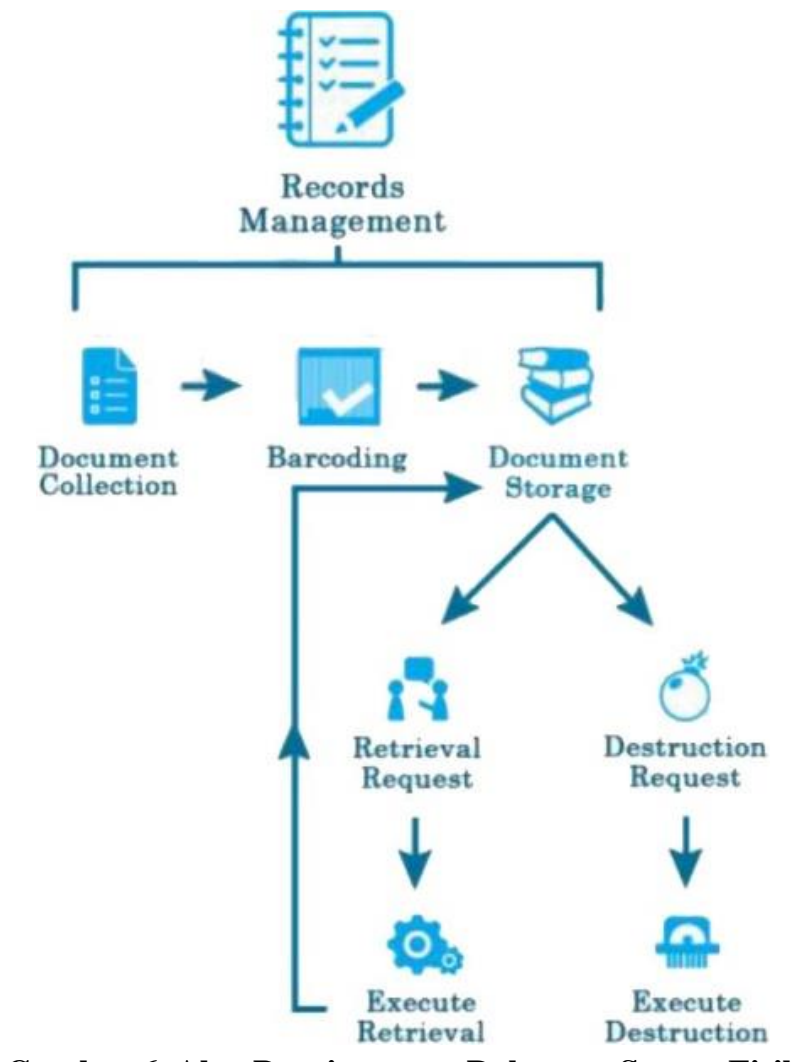

Langkah ini disebut dengan Records Management, yang kemudian pelaksanaannya berhubungan hanya dengan dokumen surat secara fisik. Dimulai dengan Document Collection yang merupakan langkah awal untuk mengoleksi atau mengumpulkan surat yang telah diproses pada kegiatan DMS. Langkah selanjutnya adalah kegiatan Barcoding yaitu menandai surat tersebut dengan suatu kode tertentu berupa bentuk batang (garis) yang akan memiliki arti tertentu. Hal ini mirip seperti bentuk kode yang ada pada suatu kemasan produk yang dijual di pasar, supermarket, dan lainnya. Kode ini bertujuan untuk meminimalisasi penulisan pada barang (dalam hal ini adalah dokumen surat) sehingga area yang digunakan untuk menandai surat pun tidak akan terlalu besar, namun dapat memuat informasi properti surat yang cukup detail. Setelah dilakukan proses Barcoding maka selanjutnya dilakukan kegiatan Document Storage (penyimpanan dokumen). Pada kegiatan ini akan ada 2 (dua) alternatif pilihan proses, yaitu Retrieval Request dan Destruction Request. Retrieval Request adalah kegiatan meneruskan kegiatan penyimpanan dokumen dikarenakan surat tersebut telah divalidasi oleh staf DMS sebagai dokumen surat yang dapat disimpan, sedangkan Destruction Request adalah kegiatan untuk menghancurkan surat dikarenakan adanya permintaan dari suatu pihak tertentu atau karena kebijakan dari perusahaan yang menyebabkan surat tidak bisa disimpan. 


\section{KESIMPULAN}

Sistem manajemen data surat digital ini akan berjalan baik secara keseluruhan karena secara dampaknya akan mempermudah proses pendokumentasian dan peminjaman surat nantinya. Implementasi sistem manajemen data surat ini diharapkan bisa memberikan kontribusi yang besar bagi perusahaan terutama pada jaman revolusi industri 4.0 sekarang ini. Masih digunakannya cara lama yaitu pendokumentasian surat secara fisik bukan berarti sistem pendokumentasian surat digital tidak bisa maksimal digunakan, melainkan menunjukkan bahwa sistem manajemen dokumentasi data secara fisik tersebut masih belum bisa ditinggalkan atau ditiadakan sepenuhnya, Karena kebijakan perusahaan sekarang masih menggunakan cara manual akibat regulasi yang belum bisa dicabut semuanya. Namun, dengan Sistem yang akan diterapkan diharapkan mampu memperbaiki permasalahan yang ada pada sistem berjalan, karena fungsi-fungsi yang memudahkan seperti penerimaan berkas dari yang sekarang hanya tinggal meng-klik apabila berkas yang dikirim sudah lengkap secara administrasi. Pengembalian berkas yang telah selesai didokumentasikan secara digital pun menjadi lebih mudah dan terhindar dari kesalahan pengembalian, proses peminjaman pun nantinya menjadi lebih otomatis dimana hanya tinggal meng-klik centang untuk berkas yang akan dipinjam dan juga tinggal mengklik centang bilamana berkas telah dikembalikan. Ditambah adanya catatan perekaman, peminjaman dan pengembalian dokumen yang otomatis tersimpan.

Disarankan dalam pengembangan terhadap sistem berikutnya perlu diadakannya pengawasan yang ditujukan pada penerapan sistem usulan, sehingga jika ditemukan kelemahan serta permasalahan pada sistem usulan dapat segera diketahui dan diperbaiki, dan dalam penerapan sistem baru ini sebaiknya didukung juga oleh perangkat yang memadai dari segi manusia maupun perlengkapan/peralatannya (hardware dan software), serta dapat ditambahkan fitur-fitur yang baru, seperti staf/karyawan nantinya dapat melakukan chat (obrolan) antar pegawai via online agar pertukaran informasi dapat menjadi lebih intens sehingga pegawai dapat lebih aktif didalam menggunakan sistem ini.

\section{DAFTAR PUSTAKA}

A Sugiarto, YB Silintowe, LN Kartika. 2014. Pengembangan Sistem Kearsipan Elektronik Berbasis ClientServer: Studi Pada Kantor Yayasan Perguruan Tinggi Kristen Satya Wacana, Jurnal Teknologi Informasi Aiti 10 (1), 46-61

Amsyah, Zulkifli. 2005. Manajemen Sistem Informasi. Jakarta: Gramedia Pustaka Utama.

Analisis Perancangan Sistem Informasi Manajemen Arsip Berbasis Web Pada STIT Tebo http://ojs.pnb.ac.id/index.php/LOGIC/article/view/156

Crowther, J. R. 1995. Theory and Practice. 42. New Jersey : Humana Press

Haryanta Agustina, et al. 2017. "Perancangan Sistem Informasi Perencanaan Dan Pengendalian Bahan Baku Pada Home Industri”, jurnalSisfotek Global Vol.7. No 1.

Soedarso. 2004. Speed Reading. Jakarta: Gramedia Pustaka Utama

Suryani, dkk. 2015. Korespondensi Bahasa Indonesia. Yogyakarta: Graha Ilmu

Wahyono, Teguh. 2004. Sistem Informasi. Yogyakarta: Graha Ilmu

https://www.academia.edu/7534109/Pengertian_Sistem_Menurut_Jogiyanto_H

http://brangkas.id/sistem-penyimpanan-arsip/

https://www.cermati.com/artikel/manajemen-pengertian-manajemen-fungsi-dan-jenis-keilmuan-yang-haruskamu-tahu 